\title{
Bio-inspired catalyst compositions for enhanced oxygen reduction using nanostructured Pt electrocatalysts in polymer electrolyte fuel cells
}

\author{
Meera Parthasarathy, $\uparrow$ Ramaiyan Kannan, Kurungot Sreekumar and Vijayamohanan K. Pillai*
}

\author{
Received 5th June 2010, Accepted 22nd July 2010 \\ DOI: 10.1039/c0jm01774d
}

\begin{abstract}
Composites of Nafion with a class of bio-molecules viz., plant hormones, are explored as potential polymer electrolytes for improving the proton transport inside the catalyst layer of a $\mathrm{H}_{2} / \mathrm{O}_{2}$ fuel cell. Specifically, four nitrogenous plant hormones, two each from the class of auxins and cytokinins have been investigated, following preliminary characterization of the composite dispersions and membranes. Interestingly, the use of indole-3-acetic acid (an auxin) in the catalyst layer reveals a 30\% enhancement in Pt catalyst utilization and improved fuel cell performance by $150 \mathrm{~mW} \mathrm{~cm}^{-2}$. The effect of these bio-molecules on the kinetic and mass transport parameters has been analyzed systematically using a combination of electrochemical and spectroscopic techniques.
\end{abstract}

\section{Introduction}

Polymer electrolyte fuel cells (PEFCs) are one of the major options for achieving sustainable energy conversion for portable, stationary and automobile applications. ${ }^{1}$ One of the critical challenges in commercializing PEFCs is their high cost. The cost factor arises mainly due to the use of Pt as the catalyst, which has been addressed by various research groups by reducing the amount of Pt by using bimetallic catalysts (instead of pure $\mathrm{Pt}$ ) and by improving the utilization of $\mathrm{Pt}$ in the catalyst layer. ${ }^{2}$ Interesting reports in this area include a demonstration of the catalytic efficiency of a conducting polymer, poly(3,4-ethylenedioxythiophene) (PEDOT) and nitrogen-doped graphene for oxygen reduction to replace $\mathrm{Pt}$ altogether in the catalyst layer., However, the current densities obtained with PEDOT electrodes are very low $\left(\sim 6 \mathrm{~mA} \mathrm{~cm}^{-2}\right)$ and hence these electrodes are particularly suitable only for microfuel cells. Also the performance is significantly lower than that of $\mathrm{Pt}$ at acidic conditions ( $\mathrm{pH}=1)$ used in fuel cells that involve proton exchange membranes. Another important progress in this area is the reduction in $\mathrm{Pt}$ loading by depositing a monolayer of $\mathrm{Pt}$ on nonnoble metal cores. $^{5}$ On the other hand, improving catalyst utilization requires careful engineering of the complicated microstructure of the carbon support which consists of micropores that trap the catalyst particles eventually leading to poor interfacial contact with the polymer electrolyte (triple phase boundary). ${ }^{6}$ For instance, carbon nanofibers have been selectively decorated with $\mathrm{Pt}$ in the inner and outer walls to yield better $\mathrm{Pt}$ dispersion and higher utilization. ${ }^{7}$ On the other hand, graded-porosity electrodes have been introduced recently for improving water management and gas diffusion in PEFCs. ${ }^{8}$ Some of the most important factors related to the catalyst layer include, dissolution and diffusion of protons, $\mathrm{H}_{2}$ and $\mathrm{O}_{2}$ through

Physical and Materials Chemistry Division, National Chemical Laboratory, Dr Homi Bhabha Road, Pune, Maharashtra, India 411008. E-mail:vk.pillai@ncl.res.in

$\dagger$ Present address: Department of Chemistry, School of Chemical and Biotechnology, SASTRA University, Tirumalaisamudram, Thanjavur, Tamilnadu, India - 613402. Email: meera_p@scbt.sastra.edu the polymer electrolyte layer encapsulating the catalyst agglomerates, electronic conduction through the carbon support, partial pressure of $\mathrm{O}_{2}$, ionomer loading and Pt loading. Most of these parameters have been optimized especially in the case of Nafion-based PEFCs operating at medium temperatures (60 to $80{ }^{\circ} \mathrm{C}$ ), by improving the engineering aspects of membraneelectrode assembly (MEA) fabrication. Hence further improvement in the oxygen reduction reaction (ORR) kinetics and the fuel cell performance requires a rationale different from the existing approaches.

Increased attention is being given nowadays to bio-inspired strategies, exploiting the similarities in the functional aspects of biological systems with some of the fuel cell components. ${ }^{9}$ For instance, a number of metalloenzymes catalyzing the ORR, ${ }^{10}$ have been successfully investigated as cathode catalysts in $\mathrm{H}_{2} / \mathrm{O}_{2}$ PEFCs. However, their performance is suitable only for small power requirements like that of pacemakers and biosensors. As an alternative approach, the addition of metalloenzymes or their active sites to the state-of-the-art fuel cell cathodes is emerging rapidly. For example, alternate assemblies of metallo-porphyrins with platinum nanoparticles have been identified as tunable electrocatalysts for the ORR. ${ }^{11}$ On the other hand, cobalt phthalocyanine is found to increase the solubility of $\mathrm{O}_{2}$ in the ionomer layer encapsulating the $\mathrm{Pt}$ particles in the cathode. ${ }^{12}$ Similarly, the effect of adsorbing Uracil, a nitrogenous base found in ribonucleic acids, on the ORR activity of Pt electrodes has been investigated. ${ }^{13}$ However, almost all of the bio-inspired strategies discussed above, despite their fundamental interest, result in performance lower than that of the conventional PEFCs. Nevertheless, the performance of bio-inspired electrodes could be improved by choosing a different class of molecules other than porphyrins, nucleobases and metalloenzymes, which take part in physiological pathways more relevant to $\mathrm{H}_{2} / \mathrm{O}_{2}$ fuel cells.

In this context, plant hormones constitute one of the least explored classes of biomolecules for fuel cell applications probably due to the diversity in their molecular structures and comparatively less understood biochemical pathways compared to those in animal systems. Plant hormones are broadly classified 
a

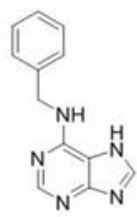

d

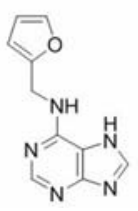

b

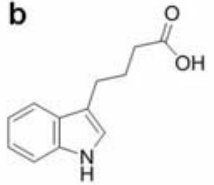

C

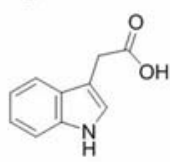

Fig. 1 Molecular structures of plant hormones used in the present study a) 6-benzylamino purine (BAP); b) indole-3-butyric acid (IBA); c) indole3-acetic acid (IAA); d) kinetin among which (a) and (d) are cytokinins whereas (b) and (c) are auxins.

as auxins, cytokinins and gibberellins based on their physiological functions. As the objective of the present work is to interface plant hormones with the proton conducting polymer (Nafion for fuel cell applications), only those molecules which are involved in proton transport related processes in biological systems will be considered (Fig. 1). Accordingly, we have chosen two cytokinins $v i z$., kinetin, 6-benzylaminopurine and two auxins viz., indole-3acetic acid (IAA) and indole-3-butyric acid (IBA) for the present study. The present investigation validates the interesting option of using plant hormones for boosting the performance of PEFCs. Moreover, this investigation may pave the way to the deployment of more natural products, or even plant extracts directly, to improve the performance of PEFCs.

\section{Results and discussion}

Before introducing the plant hormones into the catalyst layer of MEAs, their compatibility with Nafion was assessed by analyzing the respective composite dispersions and membranes. The stability of Nafion with hormone molecules was tested as follows. $5 \mathrm{wt} \%$ Nafion dispersions containing dissolved hormones analyzed using UV-visible spectroscopy reveal that there is no specific chemical interaction between Nafion and the hormone molecule. Specifically, the UV-visible spectra of the pristine hormone solutions (in ethanol) are similar to those in the presence of Nafion which have also been checked once in every $24 \mathrm{~h}$ for a period of 1 week at various hormone concentrations $\left(2.5,0.5,0.1 \mathrm{mg} \mathrm{ml}^{-1}\right)$. However, the $\mathrm{pH}$ of the Nafion dispersion is found to increase after the addition of each of the hormones, probably due to acidification of the hormone molecules by Nafion. Subsequent analysis of the composite membranes cast from the respective dispersions using FTIR spectroscopy indicates that the region of the spectra corresponding to the vibrational stretching frequency of the sulfonic acid groups (1067 and $1032 \mathrm{~cm}^{-1}$ ) is almost similar to that of the pristine Nafion membrane in the case of IBA, BAP and kinetinmodified membranes (Fig. 2). However, the FTIR spectrum of the Nafion/IAA composite membrane when expanded indicates many subtle changes in the characteristic frequencies of the sulfonic acid groups $\left(1067 \text { and } 1332 \mathrm{~cm}^{-1}\right)^{16}$ present in the

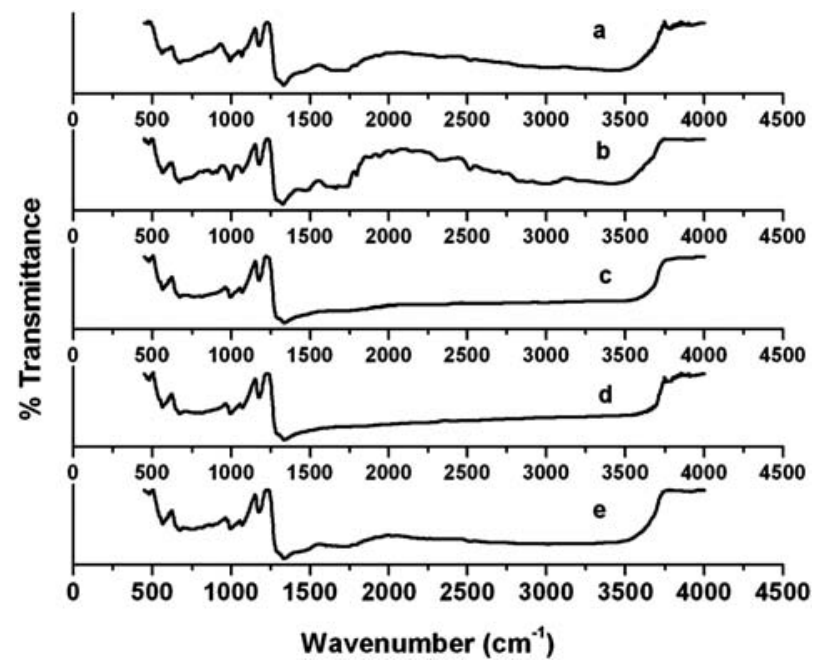

Fig. 2 Diffuse reflectance infrared spectra of a) Nafion/kinetin; b) Nafion/BAP; c) Nafion/IBA; d) Nafion/IAA with a hormone loading of $2.5 \mathrm{mg} \mathrm{ml}^{-1}$. e) Pristine Nafion membrane.

pendant chains of Nafion with a red shift of $7 \mathrm{~cm}^{-1}$ and $3 \mathrm{~cm}^{-1}$ for the symmetric and asymmetric stretching vibrations respectively. On the other hand, the differences observed in the IBA-modified Nafion film compared to the other four samples in the region between $1800 \mathrm{~cm}^{-1}$ and $3000 \mathrm{~cm}^{-1}$ could be due to a change in water content of this membrane. In addition, the $\mathrm{C}-\mathrm{C}_{s t r}$ frequency is found to be lower than that of pristine Nafion by 17 $\mathrm{cm}^{-1}$, indicating a weakening of the $\mathrm{C}-\mathrm{C}$ bonds, which could also be one of the probable reasons for the poor mechanical stability observed in the case of the composite membranes compared to that of a pristine Nafion membrane. On the other hand, thermal analysis shows that there is no significant effect of hormone incorporation on the thermal stability of Nafion membrane.

Further, the electrochemical stability of the composite membranes could be evaluated from solid state cyclic voltammetry performed using a home-made all-solid-state

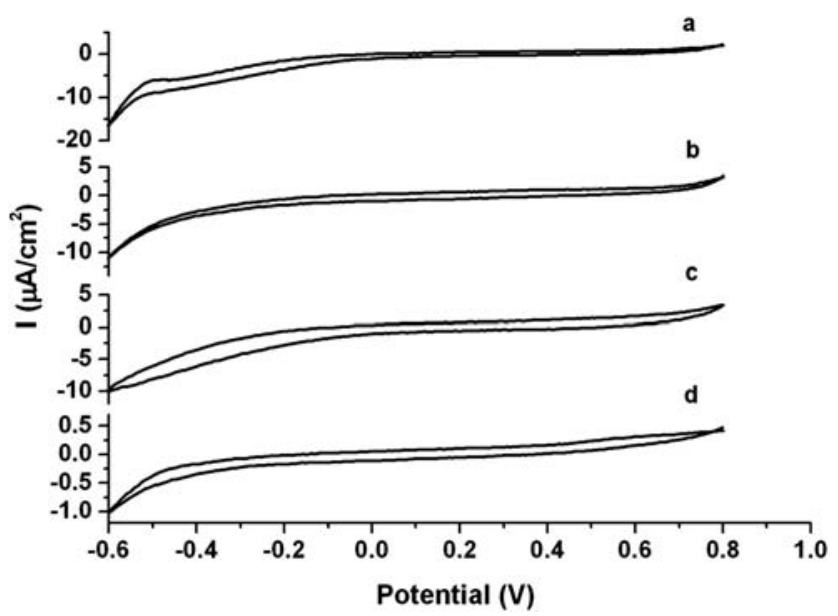

Fig. 3 Solid-state cyclic voltammograms of a) Nafion/kinetin; b) Nafion/IBA; c) Nafion/BAP; d) Nafion/IAA membranes with a hormone loading of $2.5 \mathrm{mg} \mathrm{ml}^{-1}$. Working electrode: Pt disk; counter electrode: $\mathrm{Pt}$ wire; reference electrode: $\mathrm{AgCl}$ coated $\mathrm{Ag}$ wire. 
electrochemical cell. ${ }^{14}$ Accordingly, Fig. 3 shows the solid state voltammograms of the composite membranes, with all of them exhibiting a considerably wide electrochemical potential window, except for the Nafion/kinetin membrane, which shows a small anodic wave at about $-0.5 \mathrm{~V} v$ s. $\mathrm{Ag} / \mathrm{AgCl}$ probably due to the oxidation of kinetin. ${ }^{17}$ This could also be compared to the observation that the Nafion/kinetin composite membrane, which is originally colorless, turns black when aged for 2 days.

Thus the above preliminary investigations reveal that the hormones can serve as proton conducting conduits in the Nafion matrix without significant impact on the chemical structure and thermal stability of the polymer electrolyte membrane, indicating their possible application in PEFCs. However, the poor mechanical stability of the resulting membrane precludes the deployment of the composite membranes directly as electrolytes in fuel cells. Hence, as an alternative approach, we proceed further by employing the Nafion/hormone composite dispersions as binders in the catalyst layer of the fuel cells.

Having proved their compatibility with Nafion membranes we carried out fuel cell polarization experiments to evaluate their influence in increasing the $\mathrm{Pt}$ utilization. Fig. 4a shows the
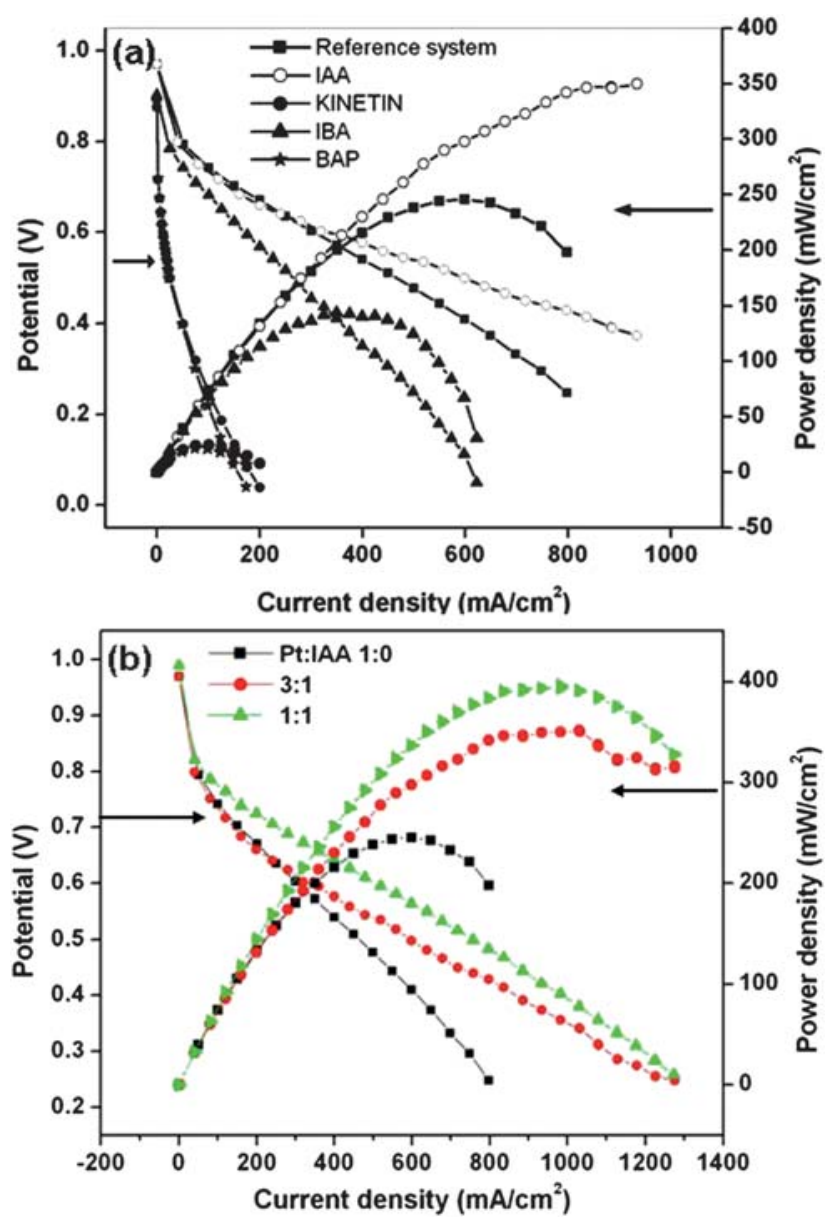

Fig. 4 Single cell polarization plots of MEAs measured at $60{ }^{\circ} \mathrm{C}$ using Nafion 115 as the polymer electrolyte membrane. (a) With different hormones and Nafion (reference system) binder in the catalyst layer. (b) Single cell polarization plots of MEAs with varying amounts of IAA in the catalyst. superimposed steady state polarization plots of $\mathrm{H}_{2} / \mathrm{O}_{2}$ fuel cells (at $60{ }^{\circ} \mathrm{C}$ ) containing Nafion 115 membrane as the polymer electrolyte with different hormones in the catalyst layer. While the maximum performance reported for the system built with state-of-the-art technology is $600 \mathrm{~mW} \mathrm{~cm}{ }^{-2}$, the performance obtained with the fuel cell design and testing procedures employed in the present study is $250 \mathrm{~mW} \mathrm{~cm}^{-2}$, which is used as the benchmark (denoted as the 'reference system'). An interesting enhancement in the fuel cell performance (by $100 \mathrm{~mW} \mathrm{~cm}^{-2}$ ) is observed for the MEA containing IAA in the catalyst layer compared to the reference system. On the other hand, the rest of the hormones exhibit only poor performance compared to the reference system with the cytokinins (BAP and kinetin) showing very poor performance compared to that with the auxin, IBA. While the $\mathrm{pH}$ of the composite dispersions and the electrochemical stability window of the corresponding membranes are almost similar, only IAA is capable of enhancing the performance of the PEFC. Although specific reasons for this discrimination could not be identified, which may require in situ spectroscopic examination of the fuel cell under operation, a probable reason could be the difference in chemical stability of the hormones in the presence of the reactive intermediates produced during the fuel cell reactions. Also, in this context, special mention is to be made of the auxin, indole-3-acetic acid (IAA), a powerful plant hormone capable of stimulating a number of functions at in vivo concentrations as low as $10^{-8}$ M. ${ }^{18}$ There is an astonishing correspondence of its physiological activity with the critical functional aspects of the catalyst layer. ${ }^{9 a}$ More specifically, IAA is known to trigger proton pumps across plasma membranes resulting in the acidification of protoplasts to effect cell elongation; ${ }^{19}$ reduce molecular oxygen to superoxide radical ion and disintegrate hydrogen peroxide $\left(\mathrm{H}_{2} \mathrm{O}_{2}\right)$ to a hydroxyl radical to create oxidative stress ${ }^{20}$ and impart better permeability of ions through the cell membranes. ${ }^{21}$ It should be noted that the disintegration of the $\mathrm{H}_{2} \mathrm{O}_{2}$ intermediate is the ratedetermining factor in the two-step $\mathrm{O}_{2}$ reduction mechanism at fuel cell cathodes. Nevertheless, the indole derivative, IAA, is quite different in its reactivity compared to $N$-heterocycles such as imidazole, pyrazole and benzimidazole, deployed frequently as electrolytes in PEMs due to the presence of both proton-donor as well as acceptor nitrogen atoms. ${ }^{21}$

The rest of the study is focused on exploring the effect of IAA on various performance parameters as it gave the maximum performance. Accordingly, Fig. $4 \mathrm{~b}$ shows superimposed steady state polarization plots of $\mathrm{H}_{2} / \mathrm{O}_{2}$ fuel cells (at $60{ }^{\circ} \mathrm{C}$ ) containing a Nafion 115 membrane as the polymer electrolyte, with different concentrations of IAA in the catalyst layer. The amount of IAA is expressed as its ratio by weight to the amount of Pt loaded in the catalyst layer. Thus the catalyst composition of the MEAs represented in the present figure involves $\mathrm{Pt}$ : IAA ratios, $1: 0$, $3: 1$ and $1: 1$. The excellent enhancement in performance of $1: 1$ MEA compared to that of the 1:0 MEA, by $150 \mathrm{~mW} \mathrm{~cm}^{-2}$ as verified by three replicated measurements with 20-25 cycles of operation in each measurement confirms the enhanced kinetics. The fuel cell performance (i.e., power density) is found to increase with increasing proportions of IAA in the catalyst layer, and attains a maximum at the $1: 1$ ratio and falls back below the performance of the $1: 0$ cell by $15 \mathrm{~mW} \mathrm{~cm}^{-2}$ in the case of $2: 3$ Pt : IAA composition (data not shown). The enhanced 
performance of the composite electrodes could be attributed to the ability of IAA in assisting Pt in ORR catalysis. This can be easily seen at low over potentials $(>300 \mathrm{mV})$ where the ORR kinetics plays a crucial role. For example, in Fig. 4a, at $0.6 \mathrm{~V}$, IAA based MEA gives a current density of $380 \mathrm{~mA} \mathrm{~cm}^{-2}$ against the $310 \mathrm{~mA} \mathrm{~cm}{ }^{-2}$ of the reference system while other hormone based MEAs give in the range of only 50 to $180 \mathrm{~mA} \mathrm{~cm}$. Similarly in MEAs with varying IAA concentration, a maximum of $450 \mathrm{~mA} \mathrm{~cm}^{-2}$ is observed suggesting that a significant role is played by IAA in enhancing the ORR kinetics. In addition, the extension of the ohmic polarization region to offer higher current densities in IAA-modified cells signifies faster mass transport of species (viz., $\mathrm{H}^{+}, \mathrm{O}_{2}, \mathrm{H}_{2}$ ) to the Pt catalyst, which is interestingly in accordance with the well-known ability of IAA to trigger the transport of ions across cell membranes. ${ }^{19}$ For example at $0.4 \mathrm{~V}$, the reference system gives a current density of only $600 \mathrm{~mA} \mathrm{~cm}^{-2}$ while the IAA based MEA gave $900 \mathrm{~mA} \mathrm{~cm}{ }^{-2}$ suggesting the improved mass transport and higher access of Pt nanoparticles that might have been buried in the micropores of the supporting carbon material. However, there is not much change in the open circuit potentials indicating that the incorporation of IAA does not alter the redox equilibrium of the cell.

Subsequently, to discriminate the influence of IAA on various charge transport parameters, the MEAs are further examined by the electrochemical impedance technique in the frequency range of $100 \mathrm{mHz}$ to $100 \mathrm{kHz}$ by simultaneously passing humidified $\mathrm{H}_{2}$ and $\mathrm{O}_{2}$ gases in the anode and the cathode compartments respectively at $60{ }^{\circ} \mathrm{C}$ (Fig. 5a). As previous reports have clearly demonstrated that the cell impedance under similar conditions is essentially influenced by ORR ${ }^{22}$ the impedance measurement in this work involves a two-electrode system with the anode serving as both auxiliary and reference electrode while the cathode serves as the working electrode. The intercept at the real axis in the high frequency part of the Nyquist ( $-Z(\operatorname{Im})$ vs. $Z(R e))$ plots shows that the overall cell resistance decreases with increasing IAA content from an $\mathrm{R}_{\mathrm{S}}$ value of $0.09 \Omega$ for MEA without IAA to $0.065 \Omega$ for the $1: 1$ MEA after which $R_{\mathrm{s}}$ starts increasing with further increase in IAA concentration (inset top left Fig. 5a). This suggests that apart from providing higher access of $\mathrm{Pt}$ nanoparticles, IAA increases the transport of ions inside the electrode thereby decreasing the overall cell resistance. While the Nyquist plots at open circuit potential do not exhibit any semicircular behavior corresponding to charge transfer control, those at overpotentials ( $\left.\eta=E_{\text {appl }}-E_{\text {equil }}\right)$ higher than $60 \mathrm{mV}$ indicate semicircular behavior at lower frequencies. The overall impedance behavior at $\eta=180 \mathrm{mV}$, shown in Fig. 5a, signifies a charge transfer process with a single time constant similar to that reported for similar systems controlled predominantly by ORR at low overpotentials $\left(\eta<200 \mathrm{mV}=E_{\text {appl }}-E_{\text {equil }}\right){ }^{22}$ This indeed corresponds to the activation polarization region in steady-state polarization plots. When the semicircular region is fitted using the complex non-linear least squares (CNLS) method, with a simple equivalent circuit shown in the inset of Fig. $5 \mathrm{a}$, an interesting decrease in the parallel resistance $\left(\mathrm{R}_{\mathrm{p}}\right)$ with increasing IAA content is observed. The same trend in $R_{p}$ is found at a range of overpotentials from $80 \mathrm{mV}$ to $200 \mathrm{mV}$ (Fig. 5b). Thus the impedance studies indicate that incorporation of IAA in the catalyst layer helps to improve fuel cell performance mainly by improving the ORR kinetics.
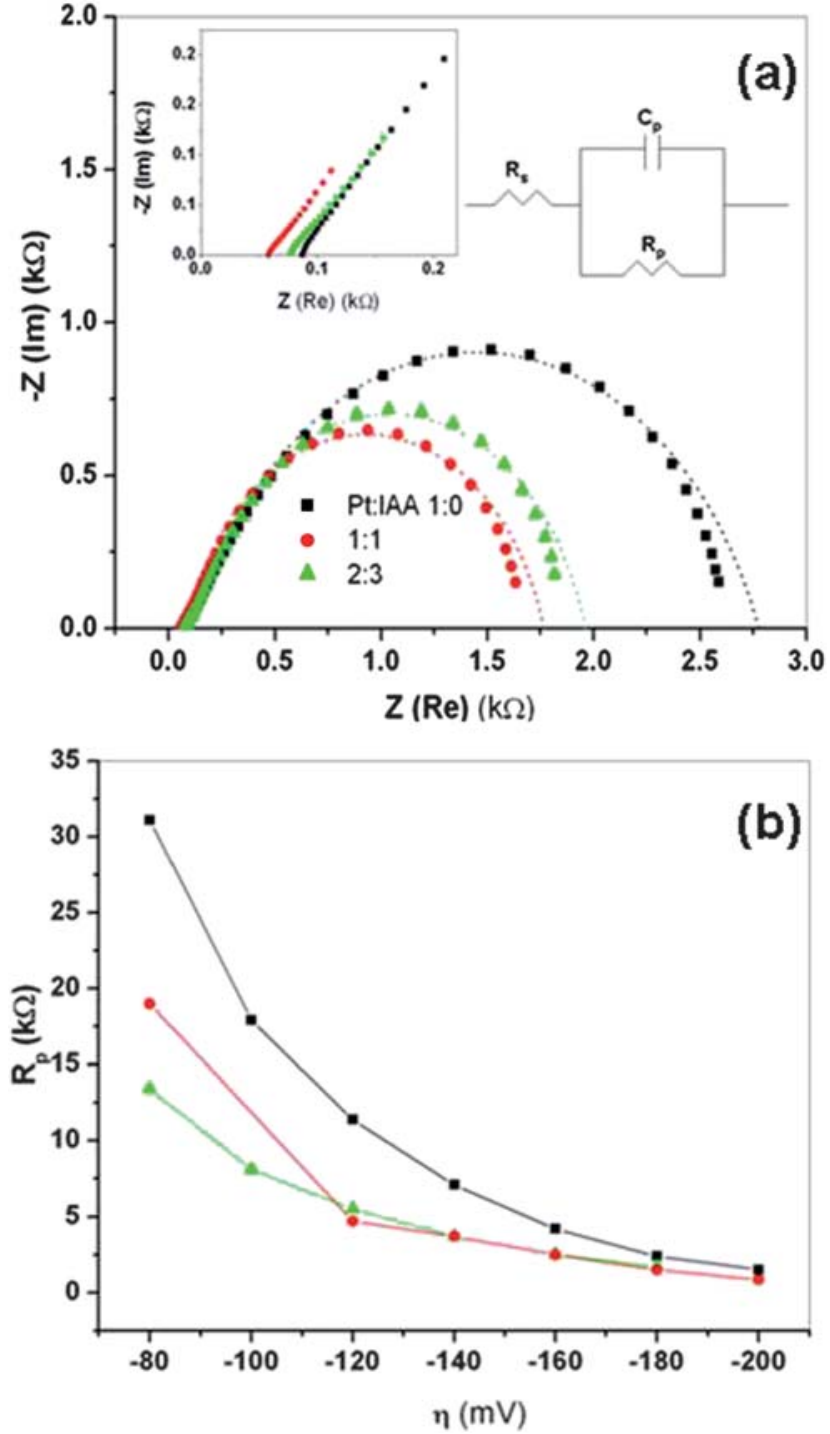

Fig. 5 (a) Electrochemical impedance Nyquist (-Z(Im) versus $Z(R e)$ ) plots for MEAs with and without IAA in the catalyst layer at a polarization of $180 \mathrm{mV}$ at $25{ }^{\circ} \mathrm{C}$. The symbols (- - - - - - - represent experimental data and the dotted lines correspond to the fitted curve using an equivalent circuit consisting of a single resistor in series with a parallel RC component. Inset top right: Electrical equivalent circuit used for fitting the impedance data. Inset top left: expansion of high frequency part; (b) variation of $R_{\text {parallel }}\left(R_{p}\right)$ with polarization with IAA content in the catalyst layer.

Subsequently, we proceed now to explore the influence of IAA on Pt catalyst utilization. The catalyst slurries with various ratios of Pt: IAA have been examined using cyclic voltammetry at a glassy carbon electrode in $0.5 \mathrm{M} \mathrm{H}_{2} \mathrm{SO}_{4}$. Accordingly, Fig. 6 shows representative cyclic voltammograms (CVs) of a $1: 0$ catalyst slurry (without IAA) and $1: 1$ slurry superimposed on the $\mathrm{CV}$ of IAA. The absence of significant redox peaks in the case of IAA (designated as $0: 1$ in Fig. 6) and the stability of the response with subsequent potential scans indicates that the hormone is considerably stable under the experimental conditions. This could be verified with reference to earlier reports on the stability of IAA in aqueous systems. ${ }^{19}$ Significant 


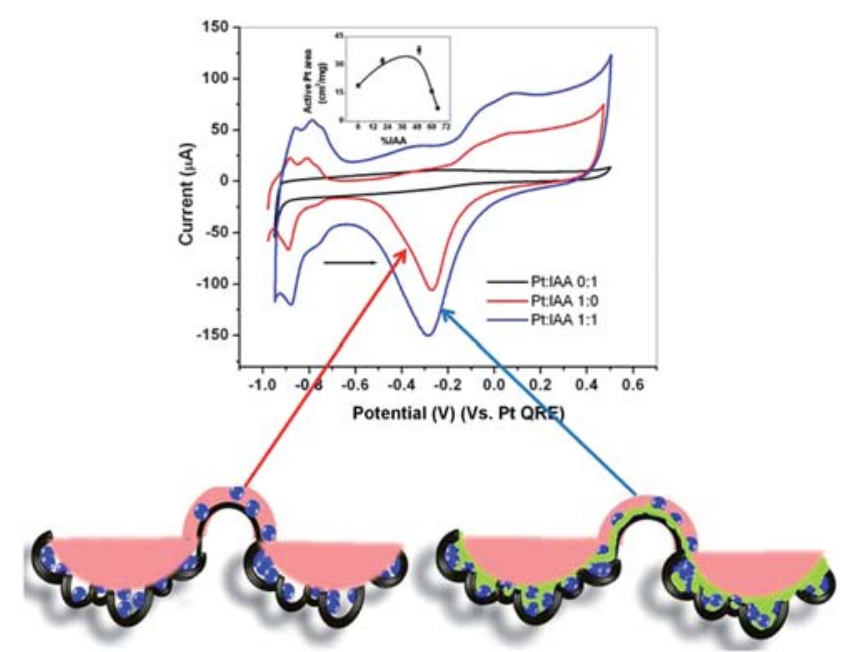

Fig. 6 Cyclic voltammograms of catalyst slurries with different amounts of IAA coated on a $1.5 \mathrm{~mm}$ diameter glassy carbon working electrode in $\mathrm{N}_{2}$ saturated $0.5 \mathrm{M} \mathrm{H}_{2} \mathrm{SO}_{4}$ at a scan rate of $50 \mathrm{mV} \mathrm{s}^{-1}$. A Pt wire was used as the quasi reference electrode and a Pt foil was used as the auxiliary electrode. Inset: Electroactive Pt area of catalyst slurries with different amounts of IAA.

enhancement (by a factor of 2) in the areas under the $\mathrm{O}_{2}$ reduction and $\mathrm{H}_{2}$ adsorption peaks for the same amount of $\mathrm{Pt}$ on the electrode is evident in the case of $1: 1$ catalyst layer compared to that without IAA $(1: 0)$ (Fig. 6). The enormous enhancement in peak area in the present case clearly reveals that IAA remarkably increases the electroactive area of the Pt catalyst and facilitates the mass transport of species to the catalyst surface. The catalyst utilization with and without IAA is calculated as follows. The charge corresponding to double layer capacitance was subtracted. After double layer correction, the electroactive $\mathrm{Pt}$ area was calculated based on the finding that a smooth polycrystalline Pt-surface shows a hydrogen adsorption charge of $210 \mu \mathrm{C} \mathrm{cm}^{-2}$. By comparing the electroactive Pt area with the overall geometric area of the Pt surface (manufacturer's specification) the catalyst utilization is obtained.

It has been found that the electroactive Pt area is doubled after the addition of IAA to the catalyst layer (peak area $\mathrm{Pt}_{\mathrm{IAA}, 1: 0=}$ $19 \mathrm{~m}^{2} \mathrm{~g}^{-1}$; peak area $\mathrm{Pt}$ : IAA, $1: 1=38 \mathrm{~m}^{2} \mathrm{~g}^{-1}$ ). Most importantly, this enhancement in electroactive $\mathrm{Pt}$ area amounts to an increase in catalyst utilization from $30 \%$ to $60 \%$ calculated with respect to the geometrical surface area of Pt. Interestingly, this implies that the Pt loading in fuel cells can be reduced by $30 \%$ by the mere addition of a few milligrams of the plant hormone in the catalyst layer. Moreover, the effect of increasing IAA concentration in the catalyst layer (inset Fig. 6) follows a trend similar to that observed in the polarization and impedance behavior of the corresponding MEAs. In addition, the increase in double layer capacitance (calculated from the non-Faradaic part of the CVs) by $50 \mathrm{~F} \mathrm{~g}^{-1}$ in the $1: 1$ slurry compared to that without IAA indicates that the $\mathrm{Pt}$ nanoparticles buried in the micropores might be accessed and thus result in an improved electrocatalystelectrolyte interface.

The enhancement in catalyst utilization after adding IAA to the catalyst layer can be explained as follows. The carbon support used in the catalyst layer has a complicated microstructure with pores of two different sizes namely the 'macro' pores formed between a group of agglomerates of catalyst particles and the 'micro' pores representing the spaces between the particles constituting each agglomerate. ${ }^{6 b}$ Vulcan $\mathrm{XC}-72$ is the most commonly used carbon support in fuel cells due to its high surface area $\left(229.3 \mathrm{~m}^{2} \mathrm{~g}^{-1}\right)$. However around $47 \%$ of it consists of micropores. ${ }^{23}$ An uninterrupted network of protons between the catalyst particles and the polymer electrolyte membrane (PEM) is a crucial factor in cell performance. ${ }^{13}$ This is ensured in a PEM by using a solution of the ionomer as binder in the catalyst layers. However, the high molecular weight of the ionomer ( 6000 to $7000 \mathrm{~g} \mathrm{~mol}^{-1}$ ) precludes it from entering the 'micro' pores to access catalyst particles struck up in them. For example, Kim et al. have demonstrated significant changes in the pore structure of the catalyst layer, upon manipulating the aggregate size of polymer electrolyte, poly(benzimidazole) in different solvents. ${ }^{24}$ Nevertheless, this problem could be effectively overcome if a low-molecular weight proton conductor $\left(\sim 100-300 \mathrm{~g} \mathrm{~mol}^{-1}\right)$ is used along with the ionomer dispersions as binders in the catalyst layer, as depicted in Fig. 6.

In order to investigate whether IAA affects the kinetics of oxygen reduction reaction in the fuel cell, the catalyst/electrolyte interface has been studied using the rotating disk electrode (RDE) method. Linear sweep voltammograms (LSV) of the catalyst layers with $\left(W_{\mathrm{Pt}}: W_{\text {IAA }} 1: 1\right)$ and without IAA in $\mathrm{O}_{2}$ saturated $0.5 \mathrm{M} \mathrm{H}_{2} \mathrm{SO}_{4}$, superimposed with the LSV of IAA at an electrode rotation speed of $900 \mathrm{rpm}$ are shown in Fig. 7. The absence of a significant redox response in the case of IAA indicates that the molecule itself does not catalyze oxygen reduction in the absence of platinum. On the other hand, a remarkable enhancement in the limiting current for $\mathrm{O}_{2}$ reduction is observed in the presence of IAA in the catalyst layer $\left(j_{\mathrm{L}(1: 0)}=0.4 \mathrm{~mA}\right.$ $\left.\mathrm{cm}^{-2} ; j_{\mathrm{L}(1: 1)}=1 \mathrm{~mA} \mathrm{~cm}^{-2}\right)$.

This is further confirmed by varying its concentration in the catalyst layer, when the limiting current density increases with increasing IAA content upto $1: 1$ (Pt: IAA) after which it

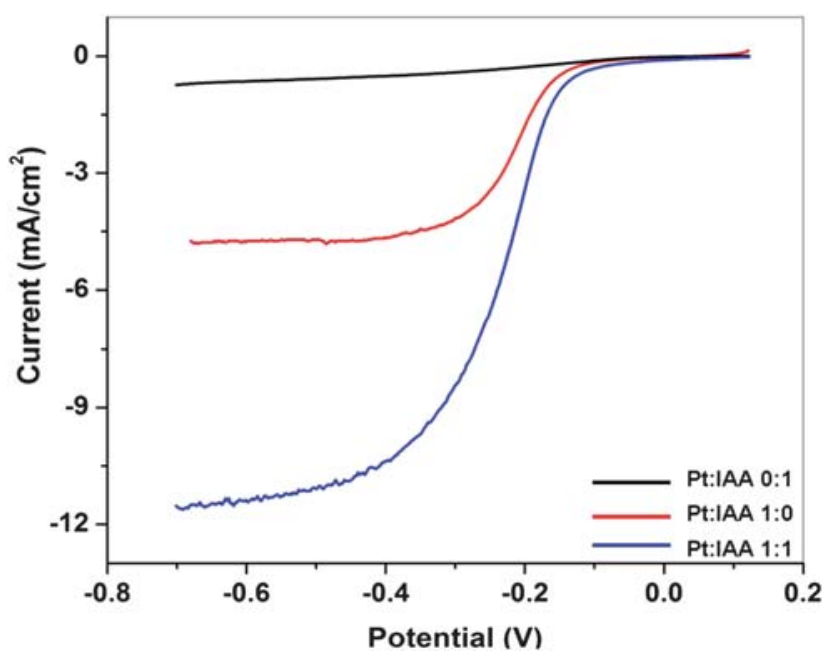

Fig. 7 Steady state voltammograms of the catalyst slurries coated on a glassy carbon working electrode $\left(1.5 \mathrm{~mm}\right.$ diameter) in $\mathrm{O}_{2}$ saturated 0.5 $\mathrm{M} \mathrm{H}_{2} \mathrm{SO}_{4}$ at a scan rate of $10 \mathrm{mV} \mathrm{s}^{-1}$ obtained by rotating the electrode at a speed of $900 \mathrm{rpm}$. Excellent enhancement in the limiting current for ORR is observed after introducing IAA in the catalyst layer. 
decreases. It should be noted that previous RDE studies under similar conditions have clearly revealed that the polymer electrolyte film on the $\mathrm{Pt}$ surface does not affect the kinetics or mechanism of ORR except for its effect on reducing the diffusion coefficient of $\mathrm{O}_{2}$ by 2.5 times compared to that in $0.1 \mathrm{M}$ $\mathrm{H}_{2} \mathrm{SO}_{4}{ }^{25,26}$ Accordingly, kinetic parameters were calculated using the Levich-Koutecky expression,

$$
\frac{1}{j}=\frac{1}{j_{k}}+\left[\frac{1.613 v^{1 / 6}}{n F C_{o_{2}} D_{O}^{2 / 3} \omega^{1 / 2}}\right]
$$

where, $j_{k}=n F k C_{O_{2}}$ in which, $n=$ number of electrons transferred, $F$ is the Faraday constant $\left(96485 \mathrm{C} \mathrm{mol}^{-1}\right), k$ is the apparent rate constant $\left(\mathrm{cm} \mathrm{s}^{-1}\right), C_{O_{2}}$ is the concentration of dissolved oxygen $\left(1.26 \times 10^{-6} \mathrm{~mol} \mathrm{~cm}^{-3}\right),{ }^{27,28} D_{o}$ is the diffusion coefficient of oxygen $\left(1.93 \times 10^{-5} \mathrm{~cm}^{2} \mathrm{~s}^{-1}\right)$, $\omega$ is the angular rotation speed of the electrode (radians $\mathrm{s}^{-1}$ ) and $\nu$ is the kinematic viscosity of the electrolyte $\left(1.009 \times 10^{-2} \mathrm{~cm}^{2} \mathrm{~s}^{-1}\right) .{ }^{28}$ In addition, the apparent rate constants $(k)$ were calculated for $\mathrm{O}_{2}$ reduction from the intercepts of $j^{-1}$ versus $\omega^{-1 / 2}$ plots using the values reported for the solubility of $\mathrm{O}_{2}$ i.e., $1.22 \times 10^{-6} \mathrm{~mol} \mathrm{~cm}{ }^{-3} .{ }^{27}$ The rate constant values are comparable to the reported ones in similar systems. ${ }^{29,30}$ Further calculation using a plot of $\log \left(j_{k}\right) v s$. $\eta$ yields a value of $5.2 \times 10^{-11} \mathrm{~A} \mathrm{~cm}^{-2}$ for the exchange current density $\left(j_{o}\right)$ for oxygen reduction in the absence of IAA compared to a value of $1.9 \times 10^{-10} \mathrm{~A} \mathrm{~cm}^{-2}$ the catalyst layer with $W_{\mathrm{Pt}}: W_{\text {IAA }}$ corresponding to the $1: 1$ composition (Table 1). The $j_{o}$ values are comparable to those reported for oxygen reduction in similar systems. ${ }^{31,32}$

Thus the present investigation demonstrates the promising role of auxins and cytokinins as additives in the catalyst layer to enhance the performance of PEFCs with reduced Pt loading. However, it should be noted that the mode of action of the hormones in the catalyst layer is not clearly understood from the above results, which may require in situ spectroscopic monitoring of the fuel cell electrodes. Also, the effect of hormones on peroxide-induced degradation of Nafion, $\mathrm{Pt}$ dissolution and redeposition, the poisoning of $\mathrm{Pt}$ surface by carbon monoxide when reformed hydrogen is used as the fuel and the durability of electrode materials need to be investigated more rigorously. Although the results of only a few hormones are shown here, there are many other biomolecules, especially indole derivatives like tryptophan and melatonin which are known to follow biological pathways of relevance to fuel cells. ${ }^{33,34}$

\section{Conclusions}

In summary, the beneficial role of plant hormones viz., auxins and cytokinins in enhancing the performance of low temperature $\mathrm{H}_{2} / \mathrm{O}_{2}$ PEFCs has been demonstrated in terms of ORR kinetics, catalyst utilization and fuel cell performance parameters. More specifically, the auxin, IAA is found to provide a realistic enhancement in performance compared to that of the wellestablished systems employing Pt catalyst, while majority of the reports on bio-inspired approaches have shown only nominal improvements in performance, despite their novelty and scientific interest. Thus the results of this investigation are en route to improving fuel cell performance using natural products extracted from plants and other biological systems as vital ingredients to boost the performance of fuel cells. Though the present study is concerned with $\mathrm{H}_{2} / \mathrm{O}_{2}$ PEFCs, the strategy is expected to be valid for other reactants like methanol and ethanol and the formulation may serve effective in polymer electrolyte-based systems other than fuel cells like biosensors. More significant will be the extension of these results for microbial and other types of biofuel cells.

\section{Experimental}

Nafion (5 wt $\%$ dispersion in lower aliphatic alcohols), indole-3acetic acid, indole-3-butyric acid, 6-benzylamino purine and kinetin were procured from Sigma-Aldrich chemicals Ltd. Vulcan XC-72 and $20 \mathrm{wt} \% \mathrm{Pt} / \mathrm{C}$ were procured from Arora Matthey Ltd. Deionized water from Millipore $(18 \mathrm{M} \Omega \mathrm{cm})$ was used for external humidification of the MEAs and for preparing electrolyte solutions. The Nafion/hormone composite dispersions were prepared by dissolving appropriate amount of the hormones in the commercial Nafion dispersion. The membranes were cast from the solution at a temperature of $60{ }^{\circ} \mathrm{C}$ in an airoven. UV-visible spectra were recorded at room temperature ( 25 ${ }^{\circ} \mathrm{C}$ ) using a Varian Cary50 model dual beam spectrophotometer. Diffuse reflectance FTIR spectra were recorded using a PerkinElmer Spectrum One spectrophotometer operating at a resolution of $4 \mathrm{~cm}^{-1}$. Solid-state cyclic voltammetry of the composite membranes was conducted using a setup described in our earlier report $^{14}$ with a Solartron SI 1287 electrochemical interface operated through Corrware software; $\mathrm{pH}$ measurements were carried out using a glass electrode purchased from Eutech instruments.

Table 1 Comparison of thermodynamic and kinetic parameters of MEAs and catalyst slurries with varying proportions of IAA with respect to Pt loading

\begin{tabular}{|c|c|c|c|c|c|c|}
\hline$W_{\mathrm{Pt}}: W_{\mathrm{IAA}}$ & $\begin{array}{l}\text { Open } \\
\text { circuit } \\
\text { potential }_{\text {cell }} / \mathrm{V}\end{array}$ & $\begin{array}{l}\text { Electro-active } \\
\text { Pt area } a / \mathrm{m}^{2} \mathrm{~g}^{-1}\end{array}$ & $\begin{array}{l}\text { Catalyst } \\
\text { utilization }^{a}(\%)\end{array}$ & $\begin{array}{l}\text { Apparent rate } \\
\text { constant for } \\
\text { ORR }^{b} / 10^{-4} \mathrm{~cm} \mathrm{~s}^{-1}\end{array}$ & $\begin{array}{l}\mathrm{R}_{\mathrm{s}}^{c} / \mathrm{m} \Omega \mathrm{cm}^{-2} \\
\text { electrode geometric } \\
\text { area }\end{array}$ & $J_{\mathrm{o}}{ }^{d} / \mathrm{A} \mathrm{cm}^{-2}$ Active $\mathrm{Pt}$ \\
\hline $3: 1$ & 0.92 & 32 & 50 & 0.3 & 15 & $3.4 \times 10^{-11}$ \\
\hline $1: 1$ & 0.97 & 38 & 60 & 1.6 & 11 & $1.9 \times 10^{-11}$ \\
\hline $2: 3$ & 0.97 & 16 & 25 & 3.2 & 15 & $3.9 \times 10^{-11}$ \\
\hline
\end{tabular}

${ }^{a}$ Calculated from cyclic voltammetry of catalyst slurries in $0.5 \mathrm{M} \mathrm{H}_{2} \mathrm{SO}_{4} \cdot{ }^{b}$ Calculated from Koutecky-Levich plots derived from rotating disk electrode measurements of catalyst slurries in $\mathrm{O}_{2}$-saturated $0.5 \mathrm{M} \mathrm{H}_{2} \mathrm{SO}_{4}$ at a potential of $0.17 \mathrm{~V} v s . \mathrm{Hg} / \mathrm{Hg}_{2} \mathrm{SO}_{4}{ }^{c}$ Calculated from electrochemical impedance measurements of the MEAs by passing humidified $\mathrm{H}_{2}$ and $\mathrm{O}_{2}$ gases in the anode and the cathode compartments respectively. ${ }^{d}$ Calculated from RDE measurements using a plot of $\log \left(j_{k}\right)$ versus $\eta$. 
The fuel cell tested was a single cell with a geometric area of $5 \mathrm{~cm}^{2}$ with Nafion 115 as the polymer electrolyte membrane. The gas diffusion layer (GDL) was prepared by brushing a slurry of Vulcan XC-72, PTFE, water and cyclohexane on a carbon cloth until a carbon loading of $4 \mathrm{mg} \mathrm{cm}^{-2}$ was achieved. The GDL was heat treated at $350{ }^{\circ} \mathrm{C}$ for $30 \mathrm{~min}$. Then the catalyst ink was prepared by mixing $20 \mathrm{wt} \% \mathrm{Pt} / \mathrm{C}$, Nafion, water and isopropyl alcohol in a homogenizer for 2 min at intervals of $20 \mathrm{~s}$. The catalyst ink was then applied on the GDL by brushing so that Pt and Nafion loading were 0.5 and $0.6 \mathrm{mg} \mathrm{cm}^{-2}$ respectively for both cathode as well as anode. After applying a thin layer of Nafion over the catalyst layer for achieving optimum Pt catalyst utilization and mass transport of reactants to the catalyst layer, ${ }^{15}$ the MEA was obtained by pressing the two electrodes uniaxially with the Nafion 115 membrane in between at $110{ }^{\circ} \mathrm{C}$ at a pressure of 1 ton for $4 \mathrm{~min}$. Hormonemodified MEAs were fabricated by introducing different amounts of indole-3-acetic acid (IAA) in the catalyst layer by dissolving them in the catalyst ink (both in the cathode as well as anode). Proportions (by weight) of IAA with respect to the weight of Pt in the catalyst layer include $W_{\mathrm{Pt}}: W_{\mathrm{IAA}}: 1: 0,3: 1,2: 1,1: 1,2: 3$ and $1: 2$. The MEAs were used to form single fuel cells by passing humidified $\mathrm{H}_{2}(80 \% \mathrm{RH})$ on one electrode and humidified $\mathrm{O}_{2}$ on the other at $0.2 \mathrm{slpm}$ through serpentine flow fields designed by Electrochem Inc. The fuel cells were conditioned at $0.2 \mathrm{~V}$ for $30 \mathrm{~min}$ and polarization measurements were carried out using an Arbin fuel cell test station (Model: Arbin-001 MITS Pro-FCTS 5.0-FCTS) at $60{ }^{\circ} \mathrm{C}$. The single cells were further analyzed using electrochemical impedance with a $10 \mathrm{mV} \mathrm{rms} \mathrm{signal} \mathrm{in} \mathrm{the} \mathrm{frequency} \mathrm{range}$ $100 \mathrm{mHz}-100 \mathrm{kHz}$ and solid state cyclic voltammetry by passing $\mathrm{H}_{2}$ in the anode and $\mathrm{N}_{2}$ in the cathode.

ORR activity of the catalyst was analyzed independently in $0.5 \mathrm{M} \mathrm{H}_{2} \mathrm{SO}_{4}$ by coating a $7 \mu \mathrm{l}$ of the catalyst dispersion (in ethanol-water $2: 4 \mathrm{v} / \mathrm{v}$ ) on a $1.5 \mathrm{~mm}$ diameter glassy carbon electrode (purchased from Microdevices Ltd.) using cyclic voltammetry. The electroactive $\mathrm{Pt}$ area was determined by integrating the area under the hydrogen adsorption peaks based on the assumption of a charge of $210 \mu \mathrm{C} \mathrm{cm}^{-2}$ on polycrystalline $\mathrm{Pt}$. Based on the electroactive Pt area and the geometric area of Pt on the carbon support obtained from manufacturer's specifications, the catalyst utilization factor was calculated. In the same electrochemical cell, rotating disk electrode experiments were constructed using an Autolab controller coupled to the Autolab PGSTAT30 bi-potentiostat.

\section{Notes and references}

1 B. C. H. Steele and A. Heinze, Nature, 2001, 414, 345.

2 (a) V. R. Stamenkovic, B. S. Moon, K. J. J. Mayrhofer, P. N. Ross and N. M. Markovic, J. Am. Chem. Soc., 2006, 128, 8813; (b) J. Zhang, M. B. Vakmirovik, Y. Xu, M. Mavrikakis and R. R. Adzik, Angew. Chem. Int. Ed., 2005, 117, 2170.

3 B. W. Jensen, O. W. Jensen, M. Forsyth and D. R. MacFarlane, Science, 2008, 321, 671.

4 L. Qu, Y. Liu, J. B. Baek and L. Dai, ACS Nano, 2010, 4, 1321.

5 J. Zhang, F. Lima, M. Shao, K. Sasaki, J. Wang, J. Hanson and R. R. Adzik, J. Phys. Chem., 2005, 109, 22701.

6 (a) J. M. Song, S. Suzuki, H. Uchida and M. Watanabe, Langmuir, 2006, 22, 6422; (b) U. A. Paulus, Z. Veziridis, B. Schnyder, M. Khunke, G. G. Scherer and A. Wokaun, J. Electroanal. Chem., 2003, 541, 77.

7 B. K. Balan, S. M. Unni and S. Kurungot, J. Phys. Chem. C, 2009, 113, 17572.

8 H. Tang, S. Wang, M. Pan and R. Yuan, J. Power Sources, 2007, 166, 41.

9 (a) W. Sun, B. A. Peppley and K. Karan, Electrochim. Acta, 2005, 50, 3359; (b) M. Yamada and I. Honma, Fuel Cells Bull., 2006, 5, 11.

10 B. G. Malmstrom, Annu. Rev. Biochem., 1981, 51, 21.

11 M. Huang, Y. Shao, X. Sun, H. Chen, B. Liu and S. Dong, Langmuir, 2005, 21, 323.

12 M. Shoji, K. Oyaizu and H. Nishide, Polymer, 2008, 49, 5659.

13 H. M. Saffarian, R. Srinivasan, D. Chu and S. Gilman, J. Electroanal. Chem., 2001, 504, 217.

14 M. Parthasarathy, C. S. Gopinath and V. K. Pillai, Chem. Mater., 2006, 18, 5244.

15 T. A. Ticianelli, C. R. Derouin and S. J. Srinivasan, J. Electroanal. Chem., 1988, 251, 275.

16 A. Gruger, A. Regis, T. Schmatko and P. Colomban, Vib. Spectrosc., 2001, 26, 215.

17 Y. Ballesteros, M. J. Gonzalez de La Huebra, P. Hernandez and L. Hernandez, Microchem. J., 2003, 74, 193.

18 I. G. Gazaryan, L. M. Lagrimini, G. A. Ashby and R. N. F. Thorneley, Biochem. J., 1996, 313, 841.

19 E. Tanimoto, Crit. Rev. Plant Sci., 2005, 24, 249.

20 T. Kawano, Plant Cell Rep., 2003, 21, 829.

21 K. D. Kreuer, A. Fuchs, M. Ise, M. Spaeth and J. Maier, Electrochim. Acta, 1998, 43, 1281.

22 M. Ciureanu and R. Roberge, J. Phys. Chem., 2001, 17, 105.

23 K. W. Park, B. K. Kwon, J. H. Choi, I. S. Park, Y. M. Kim and Y. E. Sung, J. Power Sources, 2002, 109, 439.

24 J. H. Kim, H. J. Kim, T. H. Lim and H. I. Lee, J. Ind. Eng. Chem., 2007, 13, 850

25 S. K. Zecevic, J. S. Wainright, M. H. Litt, S. Lj, Gojkovic and R. F. Savinell, J. Electrochem. Soc., 1997, 144, 2973.

26 S. Gottesfeld, I. D. Rasitrick and S. Srinivasan, J. Electrochem. Soc., 1987, 134, 1455.

27 R. N. Itoe, G. D. Wesson and E. E. Kalu, J. Electrochem. Soc., 2000, 147, 2445.

28 W. Chen, J. Kim, S. Sun and S. Chen, J. Phys. Chem. C, 2008, 112, 3891.

29 M. M. Shaijumon and S. Ramaprabhu, Appl. Phys. Lett., 2006, 88, 253105.

30 J. Prakash, D. A. Tryk and E. B. Yeager, J. Electrochem. Soc., 1999, 146, 4145.

31 A. Parthasarathy, S. Srinivasan and J. Appleby, J. Electrochem. Soc., 1992, 139, 2530 .

32 P. D. Beattie, I. V. Basura and S. Holdcraft, J. Electroanal. Chem., 1999, 468, 180.

33 L. W. Chung, X. Li, H. Sugimoto, Y. Shiro and K. Morukama, J. Am. Chem. Soc., 2008, 130, 12299.

34 R. J. Reiter, D. X. Tan, L. C. Manchester and W. Qi, Cell Biochemistry and Biophysics, 2001, 34, 237. 